Original Article

\title{
The outcome of Posterio-lateral Decompression and Transpedicle Fixation for Thoracic Spine Tuberculosis
}

\author{
Zahid Khan, Seema Sharafat, Muhammad Usman, Farooq Azam, Pir-Tufail Ahmad, Shumaila Gul, \\ Aziz-ur-Rehman \\ Department of Neurosurgery, Lady Reading Hospital, Peshawar - Pakistan
}

\begin{abstract}
Objective: The study assessed the outcome of posterio-lateral decompression and trans-pedicle fixation for thoracic spine tuberculosis.

Materials and Methods: An observational, cross-sectional study was conducted at the Department of Neurosurgery, Lady Reading Hospital, Peshawar. All those patients who had undergone posterio-lateral decompression and trans-pedicle fixation for thoracic spine tuberculosis were included. Both genders with ages more than 14 years were included in our study. Ethical committee approval was taken. Pre-designed proforma was used for data entry. Patients' data were analysed through SPSS software.
\end{abstract}

Results: A total of 31 patients with tuberculous spondylodiscitis were studied. The age ranged from $15-57$ years with a mean of $37.74 \pm 10.07$ years. Most of the patients with thoracic TB were male 54.8\% (17/31). Pain improved in all the patients and neurology improved in most of the cases. The dural tear was in one patient and one patient had a wound infection. There was no mortality.

Conclusions: We conclude from the study that posterior-lateral decompression and trans-pedicle fixation for thoracic spine tuberculosis is a safe procedure. It has good results in terms of pain relief and neurological improvement. This procedure has an acceptable complications rate. Therefore, it can be considered as a better alternative to other surgical procedures for thoracic spine tuberculosis.

Keywords: Posterolateral Decompression, Thoracic Spine, Spine Tuberculosis, VAS Scale, Trans-pedicle Fixation.

\section{Corresponding Author: Seema Sharafat}

Department of Neurosurgery, Lady Reading Hospital,

Peshawar - Pakistan E-mail: drusman387@gmail.com

Date of Submission: 15-10-2021

Date of Revision: 22-09-2021

Date of Acceptance: 15-11-2021

Date of Online Publishing: 31-12-2021

Date of Print: 31-12-2021

DOI: $10.36552 /$ pjns.v25i4.612

\section{INTRODUCTION}

Tuberculosis is an infectious disease caused by mycobacteria tuberculosis. ${ }^{1}$ It is more common in 3rd world countries like India, China and Pakistan. According to WHO more than 1.8 million deaths occur due to this infection. ${ }^{1,2}$ Almost $1-3 \%$ of tuberculosis involve the skeletal system. ${ }^{3}$ More than $50 \%$ of skeletal tuberculosis involve the spine. ${ }^{4-7}$ Spine tuberculosis commonly affect the 
lumbar and dorsal spine. ${ }^{8}$ Percival Pott was the 1st who reported spinal tuberculosis in $1779 .{ }^{9}$

Thoracic spine tuberculosis is important in the sense that it leads to morbidity in the form of neurodeficit, spinal deformity and instability pain. ${ }^{2}$ It can be treated either conservatively with antiTB drugs or surgery. Indications for surgery in spine tuberculosis are progressive neurodeficit, kyphotic deformity, abscess formation or failure of medical treatment with severe disabling pain. $8,0,11$

Anterior debridement and fusion is the gold standard for spine tuberculosis but prolonged surgery time, hospital stay, kyphotic deformity, more chances of pulmonary complications and difficult anatomy in the upper thoracic spine are the disadvantages of this approach. ${ }^{12,13}$ Therefore, the posterior approach is the alternative option. ${ }^{12-}$ ${ }^{14}$ In the posterior approach to the thoracic spine tuberculosis, different options are available but the one with posterio-lateral decompression and transpedicular fixation is comparatively less time consuming and associated with fewer chances of complications. ${ }^{15-18}$

As there is a limited local study on this issue, therefore this study will help us to analyze the surgical outcome of patients who undergo posterio-lateral decompression and pedicle fixation and thus will help us in managing patients with thoracic spine tuberculosis in a better way.

\section{MATERIALS AND METHODS}

\section{Study Design and Study Setting}

An observational cross-sectional study was conducted at the Department of Neurosurgery, Lady Reading Hospital, Peshawar, Pakistan from January 2017 to June 2020. Ethical committee approval was taken. Informed consent from the patients or their relatives was taken. Follow up of the patients was 3 months after surgery. The patient's outcome after surgery was assessed in terms of pain relief and neurological improvement. The severity of pain was assessed based on VAS (visual analogue scale) (Table 1) before and after surgery, while the neurology was assessed based on ASIA score (Table 2). Predesigned Performa was used for data entry. Patients' data were analyzed using SPSS software version 21 . The $p$-value $<0.05$ was considered statistically significant.

\section{Inclusion Criteria}

All those patients who undergone posterio-lateral decompression and trans-pedicle fixation for thoracic spine tuberculosis during the study period. Patients of both gender and age of more than 14 years were included.

\section{Exclusion Criteria}

Patients with recurrent tuberculosis and those unfit for surgery were excluded from the study.

\section{Operative Steps}

After general anaesthesia, the patient is put in the prone position. The level involved is identified with the help of anatomic landmarks and a C-arm. A midline incision is given with bilateral subperiosteal dissection. A pedicle screw is passed on the opposite (opposite to the foraminotomy) side in the normal vertebrae above and below. Costotransversectomy about $4-5 \mathrm{~cm}$ is done and ipsilateral facets joint is removed at the involved level. The thoracic nerve root which comes in the way is either retracted or sacrificed. The intervertebral disc along with the involved vertebra is debrided and decompression

\begin{tabular}{|lc|}
\hline Table 1: Visual Analogue Scale. & \\
Severity of Pain & VAS $(\mathbf{0}-\mathbf{1 0})$ \\
No /minimal pain & 0,1 \\
Mild pain & $2,3,4$ \\
Moderate pain & $5,6,7$ \\
Severe pain & 8,9 \\
Worst pain & 10 \\
\hline
\end{tabular}


is ensured. The trough is filled with a bone graft or mesh cage. Then ipsilateral pedicle screw and rod are fixed. Haemostasis is secured. The wound is closed in reverse order.

Table 2: ASIA score.

\begin{tabular}{cl} 
ASIA Score & $\begin{array}{l}\text { Neuro-deficit } \\
\text { (below the involved level) }\end{array}$ \\
A & No motor/No sensory function \\
B & No motor but sensory function present \\
C & Motor present but power $<3$ \\
D & Motor present power $>3$ \\
E & Normal sensory and motor function \\
\hline
\end{tabular}

\section{RESULTS}

During the studied period, we operated a total of 45 patients with infective thoracic spine spondylodiscitis of which 31 were diagnosed as TB spine after culture and histopathology of the diseased tissue.

\section{Gender Distribution}

We had 17 (54.8\%) male patients and 14 (45.2\%) female patients. The male to female ratio was 1.2 : 1.

\section{Age Distribution}

The age of the patients ranged from $15-57$ years with a mean age of $37.74 \pm 10.07$ years.

\section{Pain According to Visual Analogue Scale (VAS)}

The pain of the patients according to VAS before and after surgery is given in table 3 . There was an improvement in pain in all the patients. The improvement in pain is statistically significant $(p-$ value $=0.001$ )

\section{Neurological Status before and after Surgery}

Out of 31 patients, 28 (90.3\%) cases had neurological deficits before surgery. All the patients had some improvement in neurology at 3 months of follow up, as given in table 4 . The improvement in neurology is statistically significant $(p$-value $=0.001)$.

\begin{tabular}{|c|c|c|c|}
\hline $\begin{array}{l}\text { Severity } \\
\text { of Pain }\end{array}$ & $\begin{array}{l}\text { VAS } \\
(0-10)\end{array}$ & $\begin{array}{l}\text { Number of } \\
\text { Patients before } \\
\text { Surgery } \\
\text { n (\%) }\end{array}$ & $\begin{array}{c}\text { Number of } \\
\text { Patients } \\
\text { after Surgery } \\
\text { n (\%) }\end{array}$ \\
\hline $\begin{array}{l}\text { No/minim } \\
\text { al pain }\end{array}$ & 0,1 & $1(3.22)$ & $26(83.87)$ \\
\hline Mild pain & $2,3,4$ & $2(6.45)$ & $04(12.9)$ \\
\hline $\begin{array}{l}\text { Moderate } \\
\text { pain }\end{array}$ & $5,6,7$ & 06 (19.35) & $01(3.22)$ \\
\hline $\begin{array}{l}\text { Severe } \\
\text { pain }\end{array}$ & 8,9 & $14(45.16)$ & $00(0)$ \\
\hline worst pain & 10 & $08(25.8)$ & $00(0)$ \\
\hline
\end{tabular}

Table 4: Neurology Based on ASIA Score.

\begin{tabular}{|ccc|}
$\begin{array}{c}\text { ASIA } \\
\text { Score }\end{array}$ & $\begin{array}{c}\text { Number of Patients } \\
\text { before Surgery } \\
\mathbf{n} \text { (\%) }\end{array}$ & $\begin{array}{c}\text { Number of Patients } \\
\text { after Surgery } \\
\text { (3 Months Followup) } \\
\mathbf{n} \text { (\%) }\end{array}$ \\
A & $5(16.12)$ & $0(0)$ \\
B & $12(38.7)$ & $3(9.67)$ \\
C & $6(19.35)$ & $1(3.22)$ \\
D & $5(16.12)$ & $4(12.9)$ \\
E & $3(9.67)$ & $23(74.19)$ \\
Total & $\mathbf{3 1 ( 1 0 0 )}$ & $\mathbf{3 1}(\mathbf{1 0 0})$ \\
\hline
\end{tabular}

\section{Operative Complications}

One of the patients (3.22\%) had a dural tear during surgery. That was covered with fat and gel foam with no postoperative leak. One patient (3.22\%) had a surgical wound infection that was treated conservatively. There was no operative mortality.

\section{DISCUSSION}

Tuberculosis (TB) is an ancient disease. Previously considered to be a disease of poor and developing countries but now also common in 
developed countries due to the emergence of Acquired Immune Deficiency Syndrome (AIDS). ${ }^{19-}$ ${ }^{23}$ Spinal cord is a common site for tuberculosis apart of the pulmonary system. ${ }^{19-21}$ It is a very dangerous form of tuberculosis (TB) in the sense that it can cause bone deformity and destruction and may lead to paraplegia. ${ }^{2,3}$ The main way of treatment of spinal tuberculosis is antituberculous drugs. ${ }^{24}$

Studies have reported that spinal tuberculosis is more common in the male gender. ${ }^{25}$ In the study of 15 patients of spinal tuberculosis 9 were male patients. ${ }^{26}$ In one study of 18 patients with thoracic-lumbar spine tuberculosis reported that $2 / 3(12 / 18)$ of their patients were male. ${ }^{27}$ Some studies have reported that spine TB is more common in the female gender. ${ }^{28}$ Our results also showed that thoracic spine tuberculosis is more common (54.8\%) in males. The reason that most cases of spinal tuberculosis are common in males is not clear.

No age is immune to spinal tuberculosis. Sun and colleagues ${ }^{26}$ reported that the mean age of their patients was 54.67 years (standard deviation 10.75). Their age range was 39 to 72 years. In a study of 82 patients mean age of their patients with the tuberculous spine was 41.4 years (range 18-56 years). ${ }^{12}$ In a similar study of 21 patients with spinal tuberculosis the mean age was 43.9 years. $^{13}$ Among the 36 patients with spine tuberculosis the mean age of patients was $53.4 \pm$ 14.2 years. ${ }^{29}$ In our study comparatively younger patients (mean age 36 years) were affected with spinal tuberculosis. The possible reason for this may be that most of our population is comprised of young people.

Back pain is the most common presentation of spinal TB. One of the main indications of surgery in spinal tuberculosis is the pain of instability. ${ }^{29}$ Studies have reported that back pain improves after surgery. ${ }^{27}$ D'souza et al $^{13}$ studied 21 patients who had undergone thoracic transpedicular decompression and pedicle screws fixation and reported that all of their patients had visual analogue score improvement from 9.52 to 2.57 after surgery. In another study of 35 patients who had undergone surgery for spinal TB, the VAS score improved from a mean of $7.48(6-10)$ to $0.47(0-8) .{ }^{28}$ We had almost the same results we had improvement of pain in all the patients after surgery.

The aim of surgery in spinal tuberculosis (TB) is debridement of the lesion, decompression of nerve tissue, restore neurological function and correction of spinal deformity. The long-term cure of spinal TB includes bony fusion resulting in, to stable spine. ${ }^{30,31}$ After debridement of the diseased intervertebral disc and the vertebral body the trough is filled with bone graft or mesh cage for fusion to occur. There are more chances of non-fusion with allograft and more (10 - 40\%) chances of donor site complications with autograft. 14,23,32 Therefore, it is better to use transverse process or healthy rib bone and titanium mesh cage after debridement. ${ }^{33-35}$ We used a healthy rib or transverse process with and without a mesh cage to fill the trough.

One of the indications of surgery with spinal tuberculosis is a neurological deficit. The prevalence of neurologic involvement represents $10 \%$ to $47 \%$ of those with spinal tuberculosis. ${ }^{36}$ Huipeng et al, $^{37}$ studied 77 patients with spinal tuberculosis and reported that all (48) the patients with neurodeficit improved after surgery. In a study, Liu et al. reported that all their patients had neurological improvement after surgery. Jin et $\mathrm{al}_{,}{ }^{24}$ reported that $93.3 \%$ of their patients had neurological improvement after surgery. Xu Cui and colleagues ${ }^{25}$ reported that $84 \%(21 / 25)$ of their cases had neurological improvement to Frankel grade $\mathrm{E}$ after surgery and the rest improved to Frankel grade D. None of the patients deteriorated.

In our study one (3.22\%) patient had an intraoperative dural tear that was covered with fats and watertight closure, the patient had no CSF leak after surgery. One (3.2\%) patient had a postoperative wound infection that was treated 
conservatively. In a study of 33 patients of spinal tuberculosis, 17 cases underwent posterior decompression with interbody fusion and instrumentation. The operative complications were $5.9 \%(1 / 17) .^{39}$

There are a few limitations in the current study, small sample size, single-centre trial and not taking into account the deformity variable. Despite these limitations, this study is one of its types in the field of management of thoracic spine TB and it also lay down the foundation for further research in the field.

\section{CONCLUSION}

We conclude from the study that posterior-lateral decompression and trans-pedicle fixation for thoracic spine tuberculosis is a safe procedure. It has good results in terms of pain relief and neurological improvement. This procedure has an acceptable complications rate. Therefore, it can be considered as a better alternative to other surgical procedures for thoracic spine tuberculosis.

\section{Disclosure}

Nothing to disclose.

\section{REFERENCES}

1. WHO: Global tuberculosis report 2018. World Health Organization (WHO) 2018.

2. Moon MS. Tuberculosis of Spine: Current Views in Diagnosis and Management. Asian Spine J. 2014; 8 (1): 97-111.

3. Abuaku BK, Tan $H$, Chen $M$, Huang X. A comparative analysis of tuberculosis treatment success between Hunan Province of China and Eastern Ghana. Med Princ Pract. 2010; 19: 451-456.

4. Pigrau-Serrallach Carlos, Rodríguez-Pardo Dolores. Bone and joint tuberculosis. European Spine Journal, 2012; 22 (S4): 556-566.

5. Nagashima $H$, Yamane $K$, Nishi $T$, Hideki $N$, Teshima R. Recent trends in spinal infections: retrospective analysis of patients treated during the past 50 years. Int Orthop. 2010; 34: 395-399.

6. Ekinci $S$, Agilli M, Ekinci GH, Ersen O. Treatment of thoracic or lumbar spinal tuberculosis complicated by resultant listhesis at the involved segment. Clin Neurol Neurosurg. 2015; 128: 131-132.

7. Rasjido LV, Vargas MJ, Fajre LE, Luciardi HL. Pott disease in thoracic spine. Medicina (B Aires), 2014; 74: 391.

8. Liu Z, Wang J, Chen G-Z, Li W-W, Wu Y-Q, Xiao X, et al. Clinical characteristics of 1378 inpatients with spinal tuberculosis in general hospitals in SouthCentral China. Biomed Res Int. 2019; 2019: 11.

9. Sai-Kiran NA, Vaishya $S$, Kale SS, Sharma BS, Mahapatra AK. Surgical results in patients with tuberculosis of the spine and severe lowerextremity motor deficits: a retrospective study of 48 patients. J Neurosurg Spine, 2007; 6: 320-326.

10. Swanson AN, Pappou IP, Cammisa FP, Giradi FP. Chronic infections of the spine: surgical indications and treatments. Clin Orthop Relat Res. 2006; 444: 100-106.

11. Zhang $P$, Wei $P$, Wang $X$, Luo $C, X u Z$, Hao $Z$, et al. Minimum 5-year follow-up outcomes for singlestage transpedicular debridement, posterior instrumentation and fusion in the management of thoracic and thoracolumbar spinal tuberculosis in adults. Br J Neurosurg. 2016: 1-6.

12. Madan MS, Sudhir KM, Gopal CS, Sunil KD. Posterior-only Approach Surgery for Fixation and Decompression of Thoracolumbar Spinal Tuberculosis: A Retrospective Study. Journal of Spinal Disorders \& Techniques, 2012; 25 (7): E217E223.

13. D'souza, Areena R, Bibhudendu M, Murari L, Kalidutta D. Role of Posterior Stabilization and Transpedicular Decompression in the Treatment of Thoracic and Thoracolumbar TB. Clinical Spine Surgery, 2017; 30 (10): E1426-E1433.

14. Yin $X H$, Liu $Z K$, He BR, Ding J. Hao DJ. Single posterior surgical management for lumbosacral tuberculosis: titanium mesh versus iliac bone graft. Medicine (Baltimore), 2017; 96 (51): e9449.

15. Liu Z, Zhang $P$, Zeng $H, X u ~ Z$, Wang X. A comparative study of single-stage transpedicular debridement, fusion, and posterior long-segment versus short-segment fixation for the treatment of thoracolumbar spinal tuberculosis in adults: minimum five-year follow-up outcomes. Int 
Orthop. 2018; 42 (4): 1-8.

16. He $\mathrm{Q}, \mathrm{Xu}$ J. Comparison between the anteroposterior and anterior approaches for treating L5S1 vertebral tuberculosis. Int Orthop. 2012; 36: 345-51.

17. Zhang HQ, Li JS, Zhao SS, Shao YX, Liu SH, Gao Q. Surgical management for thoracic spinal tuberculosis in the elderly: posterior only versus combined posterior and anterior approaches. Arch Orthop Trauma Surg. 2012; 132: 1717-23.

18. Song JF, Jing ZZ, Chen B, Ai Z, Hu W. One-stage anterolateral surgical treatment for lumbosacral segment tuberculosis. Int Orthop. 2012; 36: 33944.

19. Jain AK. Tuberculosis of the spine: a fresh look at an old disease. J Bone Joint Surg Br. 2010; 2 (9): 905-913. Doi: 10.1302/0301-620X.92B7.24668.

20. Wang B, Kong L, Zhu Z, Gao W, Guo H, Wang X, et al. Recurrent complex spinal tuberculosis accompanied by sinus tract formation: causes of recurrence and clinical treatments. Sci Rep. 2018; 8: 6933.

21. Lan X, Liu XM, Ge BF. Debridement and bone grafting with internal fixation via anterior approach for treatment of cervicothoracic tuberculosis. Int Sur. 2011; 96: 358-362. Doi: 10.9738/CC62.1.

22. Moon MS. Tuberculosis of spine: contemporary thoughts on current issues and perspective views. Curr Orthop. 2007; 21: 364-379.

23. Zhong W, Liang $X$, Tang $K$, Luo $X$, Quan $Z$. Transverse process strut and titanium mesh cages in the stability reconstruction of thoracic single segment tuberculosis: a retrospective single-center cohort study. BMC Musculoskelet Disord. 2020; 21: 172.

24. Jin D, Qu D, Chen J, Zhang H. One-stage anterior interbody autografting and instrumentation in primary surgical management of thoracolumbar spinal tuberculosis. Eur Spine J. 2004; 13 (2): 11421.

25. Cui X, Ma YZ, Chen X, Cai XJ, Li HW, Bai YB. Outcomes of Different Surgical Procedures in the Treatment of Spinal Tuberculosis in Adults. Med Princ Pract. 2013; 22: 346-350.

26. Sun QP, Xiao J, Pi HL, He JW, Wu QH. Debridement and bone grafting with internal fixation via anterior approach for the treatment of tuberculosis of lower cervical vertebrae. Zhongguo Gu Shang,
2020; 25; 33 (2): 149-53.

27. Liu Z, Zhang P, Li W, Xu Z, Wang X. Posterior-only vs. combined posterior-anterior approaches in treating lumbar and lumbosacral spinal tuberculosis: a retrospective study with minimum 7-year follow-up. J Orthop Surg Res. 2020; 15: 99.

28. Yadav G, Kandwal P, Arora SS. Short-term outcome of lamina-sparing decompression in thoracolumbar spinal tuberculosis. J Neurosurg Spine, 2020 Mar. 20: 1-8.

29. Yin $X H$, Liu ZK, He BR, Ding J. Hao DJ. Single posterior surgical management for lumbosacral tuberculosis: titanium mesh versus iliac bone graft. Medicine (Baltimore), 2017; 96 (51): e9449.

30. Shi $S$, Ying $X$, Zheng $Q$, Zhu $B$, Jin $Y$, Shen J. Application of cortical bone trajectory screws in elderly patients with lumbar spinal tuberculosis. World Neurosurg. 2018; S1878-8750 (18): 3112231127.

31. Thakur K, Das M, Dooley KE, Gupta A. The global neurological burden of tuberculosis. Semin Neurol. 2018; 38 (2): 226-237.

32. Gao Y, Ou Y, Deng Q, He B, Du X, Li J. Comparison between titanium mesh and autogenous iliac bone graft to restore vertebral height through posterior approach for the treatment of thoracic and lumbar spinal tuberculosis. PLoS One, 2017; 12 (4): e0175567.

33. Cui X, Zhang Z, Ding Z. Morphometric study of transverse process of thoracic and lumbar vertebra and its significance. Chin J Clin Anat. 2015; 23 (5): 474-476.

34. Zhang $H$, Zeng $K$, Yin $X$, Huang J, Tang $M$, Guo C. Debridement, internal fixation, and reconstruction using titanium mesh for the surgical treatment of thoracic and lumbar spinal tuberculosis via a posterior-only approach: a 4-year follow-up of 28 patients. J Orthop Surg Res. 2015; 10: 150.

35. Wu W, Lyu J, Liu X, Luo F, Hou TY, Zhou Q et al. Surgical Treatment of Thoracic Spinal Tuberculosis: A Multicenter Retrospective Study. World Neurosurgery, 2018; 110: e842-e850.

36. Pola $E$, Rossi $B$, Nasto LA, Colangelo D, Logroscino CA. Surgical treatment of tuberculous spondylodiscitis. European Review for Medical and Pharmacological Sciences, 2012; 1 (2): 79-85.

37. Yin H, Wang K, Gao Y, Zhang Y, Liu W, Song Y et al. Surgical approach and management outcomes for 
junction tuberculous spondylitis: a retrospective study of 77 patients. J Orthop Surg Res. 2018; 13: 312.

38. Liu Z, Wang $\mathrm{X}, \mathrm{Xu} Z$, Zeng $H$, Zhang $P$, Peng W et al. Two approaches for treating upper thoracic spinal tuberculosis with neurological deficits in the elderly: A retrospective case-control study. Clin
Neurol Neurosurg. 2016; 141: 111-6.

39. Xu Z, Wang X, Shen X, Luo C, Zeng H, Zhang P, et al. Posterior only versus combined posterior and anterior approaches for lower lumbar tuberculous spondylitis with neurological deficits in the aged. Spinal Cord. 2015; 53 (6): 482-7.

\section{Additional Information}

Disclosures: Authors report no conflict of interest.

Ethical Review Board Approval: The study was conformed to the ethical review board requirements.

Human Subjects: Consent was obtained by all patients/participants in this study.

Conflicts of Interest:

In compliance with the ICMJE uniform disclosure form, all authors declare the following:

Financial Relationships: All authors have declared that they have no financial relationships at present or within the previous three years with any organizations that might have an interest in the submitted work.

Other Relationships: All authors have declared that there are no other relationships or activities that could appear to have influenced the submitted work.

\section{AUTHORS CONTRIBUTIONS}

\begin{tabular}{|l|l|l|}
\hline Sr.\# & Author's Full Name & Intellectual Contribution to Paper in Terms of: \\
\hline 1. & Zahid Khan & 1. Study design and methodology. \\
\hline 2. & Seema Sharafat & 2. Paper writing, referencing, data calculations. \\
\hline 3. & Muhammad Usman & 3. Data collection and calculations. \\
\hline 4. & Farooq Azam & 4. Analysis of data and interpretation of results etc. \\
\hline 5. & Pir-Tufail Ahmad & 5. Literature review and manuscript writing. \\
\hline 6. & Shumaila Gul & 6. Analysis of data and quality insurer. \\
\hline 7. & Aziz-ur-Rehman & 7. Literature review. \\
\hline
\end{tabular}

